\title{
100 MIL MORTES: O SALDO NEGATIVO DA COVID-19 NOS TELEJORNAIS BRASILEIROS
}

\author{
Viviane Gonçalves Freitas ${ }^{1}$ \\ Érica Anita Baptista²
}

Resumo:

O foco deste artigo está na cobertura feita por três importantes telejornais do Brasil - Jornal Nacional, Jornal da Band e Jornal da Record - quando do anúncio das 100 mil mortes em consequência da Covid-19, em 8 de agosto de 2020. Nosso objetivo foi compreender como se deu a disputa político-discursiva do noticiário, uma vez que a linha editorial de cada veículo também se reflete na agenda encampada por seu principal produto jornalístico. Mais do que abordagens distintas, a análise do corpus possibilitou entender como cada telejornal acionou um tipo de interdiscurso alinhado a seu público, seja adotando a perspectiva de cobrar às autoridades governamentais pela efetivação do direito universal à saúde, seja mostrando que é possível encontrar algo positivo na quarentena.

Palavras-chave: Covid-19; 100 mil mortos; telejornalismo; comunicação política; saúde pública.

Abstract:

The focus of this article is on the coverage made by three important news programs in Brazil Jornal Nacional, Jornal da Band and Jornal da Record - when the announcement of the 100,000 deaths as a result of Covid-19, on August 8, 2020. Our objective was to understand how the political-discursive dispute of the news took place, since the editorial line of each vehicle is also reflected in the agenda covered by its main journalistic product. More than different approaches, the analysis of the corpus made it possible to understand how each news program triggered a type of interdiscourse aligned with its audience, whether adopting the perspective of charging government authorities for the realization of the universal right to health, or showing that it is possible to find something good under the quarantine.

Keywords: Covid-19; 100,000 deaths; tele journalism; political communication; public health.

\section{Introdução}

Este trabalho tem como objetivo analisar a produção de sentidos por importantes telejornais brasileiros - Jornal Nacional, Jornal da Band e Jornal da Record - por ocasião dos 100 mil óbitos, em consequência da contaminação pelo novo coronavírus, a que o Brasil chegou em 8 de agosto de 2020. A partir da literatura que trata da análise do

\footnotetext{
1 É jornalista (PUC Minas), mestra em Comunicação Social (PUC Minas), doutora em Ciência Política (UnB), com residência pós-doutoral em Ciência Política (UFMG). É pesquisadora associada à Rede de Pesquisas em Feminismos e Política e ao Margem - Grupo de Pesquisa em Democracia e Justiça (DCP/UFMG). Autora de "Feminismos na imprensa alternativa brasileira: quatro décadas de lutas por direitos" (Paco, 2018), entre outras obras. E-mail: vivianegoncalvesfreitas@gmail.com

2 Doutora em Ciência Política pela UFMG com estágio na Universidade de Coimbra. Jornalista e Mestra em Comunicação Social pela PUC Minas. É pós-doutoranda no Departamento de Comunicação Social da UFMG. Integra os Grupos EME e Opinião Pública. É vice-coordenadora do curso online de extensão da UFMG "Novas ond@s na política: eleições municipais, representação e políticas públicas”. Temas de interesse: comportamento político e eleitoral; opinião pública; eleições; campanhas.
} 
discurso, consideramos os principais noticiários das três emissoras - Globo, Band e Record para compreender a narrativa construída em relação ao acontecimento selecionado, as 100 mil mortes, tendo em vista o posicionamento e o alinhamento político dos referidos canais de TV.

O avanço da contaminação pela Covid-19 tem causado no Brasil graves problemas na estrutura de saúde e (des)valorização da ciência. Além disso, a polarização política que se formou e ganhou força a partir da campanha presidencial de 2018, divide o debate público e, também, a mídia. Parte considerável da mídia de referência no Brasil vem sofrendo ataques sistemáticos por parte do governo federal, o que incide diretamente no posicionamento político das empresas de comunicação, bem como nos enquadramentos das notícias.

É a partir do exposto que este trabalho se localiza e busca explorar a narrativa dos noticiários, tendo em conta os diferentes posicionamentos políticos que as emissoras em causa ocupam e, assim, as possíveis abordagens sobre os 100 mil mortos. Este artigo se divide em quatro seções. Na primeira delas, contextualizamos a Covid-19 no Brasil, apresentando o avanço da pandemia pelo país, as trocas de gestores do Ministério da Saúde, as alterações no método de contagem para divulgação dos dados referentes à doença e a atuação da mídia nesse cenário. A segunda seção prossegue com as discussões sobre a mídia, abordando seu papel na política, tanto no cumprimento de suas funções, como a favor de seus interesses. Em seguida, a terceira parte trata dos aspectos metodológicos que guiam a análise empreendida neste trabalho. Por fim, a quarta seção se dedica à análise dos três telejornais, apontando semelhanças e dissonâncias na cobertura jornalística do dia 8 de agosto.

\section{A Covid-19 no Brasil}

Embora o primeiro caso de Covid-19 no mundo tenha sido registrado em dezembro de 2019, na província de Wuhan, na China, pesquisas posteriores já apontam a probabilidade de que a contaminação possa ter ocorrido em data anterior - talvez um mês antes (RIGUES, 2020). Segundo a Organização Mundial da Saúde (2020), essa doença infecciosa respiratória, considerada desde 11 de março, como uma pandemia devido a sua proliferação global, é causada pelo coronavírus descoberto mais recentemente e que se tornou conhecido a partir da primeira notificação chinesa. 
Em 22 de agosto de 2020, de acordo com levantamento da Agence France-Presse (AFP) a partir de dados oficiais, 23 milhões de pessoas já teriam sido infectadas pelo vírus em todo mundo, ceifando a vida de mais de 800 mil pacientes. Neste momento, os Estados Unidos eram o país mais afetado pela doença, com 5,6 milhões de casos e mais de 175 mil mortos (AFP, 2020). Na América Latina, as desigualdades já acentuadas se aprofundaram ainda mais durante a pandemia, num contexto de aumento do desemprego, saneamento básico e serviços de saúde precários que impossibilitam medidas básicas de higienização e atendimento, com quadro de quase 255 mil vítimas e mais de 6,5 milhões de infectados (AFP, 2020). Apenas no Brasil, até as $13 \mathrm{~h}$ do dia 23 de agosto de 2020, eram 114.469 óbitos e 3.589.469 casos registrados, de acordo com o Consórcio de Veículos de Imprensa, baseado em dados das secretarias estaduais de saúde $(G 1,2020)$. O número de 100 mil vítimas foi confirmado oficialmente em 8 de agosto.

Conforme apresentado na edição do Jornal Nacional integrante do corpus de análise deste artigo, a evolução da doença tem sido cada vez mais rápida e agressiva, sendo o tempo entre marcas históricas cada vez menor. Do primeiro caso registrado no Brasil (em 26 de fevereiro) até chegar a 1 milhão de infectados, no dia 19 de junho, foram quase quatro meses. Menos de 30 dias depois, em 16 de julho, já havia 2 milhões de notificações. Em 8 de agosto, apenas 23 dias depois, os registros já somavam 3.013.369 pessoas infectadas pelo novo coronavírus.

Quanto às mortes em consequência da Covid-19, o primeiro registro é de 17 de março, em São Paulo, ou seja, 20 dias após a notificação da primeira pessoa infectada no país. Após 71 dias, em 25 de maio, já eram mais de 25 mil óbitos devido à doença. 0 Brasil registrou mais de 50 mil vítimas em 20 de junho, num intervalo de apenas 24 dias. Em 15 de julho, no período de 25 dias do último grande referencial, mais de 75 mil pessoas já haviam perdido a vida. E, em 8 de agosto, segundo o levantamento do Consórcio de Veículos de Imprensa, 100.543 brasileiros haviam morrido em razão da doença.

Mesmo sendo estes números alarmantes, especialistas ressaltam que é possível que haja subnotificação de casos no mundo e no Brasil, principalmente, pelo pequeno percentual de testagem da população. Prado et al., em estudo publicado na Revista Brasileira de Terapia Intensiva, em junho de 2020, afirmam que as subnotificações impedem que os governantes conheçam a real situação da pandemia no país, o que interfere, inclusive, nas medidas de controle. Em maio, a estimativa era de que o número de infectados poderia ser 14 vezes maior do que os registros contabilizados pelo Ministério 
da Saúde, uma vez que apenas os casos mais graves estavam sendo testados (ZIEGLER, 2020).

Além disso, não há dados estratificados da população brasileira, com abrangência das 27 unidades da Federação, que deem conta de especificar questões como raça/cor, classe social, local de moradia e comorbidades, por exemplo, e que poderiam subsidiar ações mais direcionadas para determinados grupos. Assim, embora ainda não haja evidências científicas de que a mortalidade em razão da infecção por Covid-19 estaria associada à raça/cor, especialistas entendem que a falta de saneamento básico, as condições precárias de moradia e a alimentação deficiente, entre outros fatores diretamente ligados a desigualdades sociais, poderiam aumentar a letalidade entre a população negra, uma vez que essa parcela tem maior incidência de comorbidades (hipertensão, diabetes, tuberculose, entre outras), o que agrava a infecção pelo novo coronavírus, além do menor acesso a tratamentos de saúde (FREITAS, 2020).

No contexto do estado de calamidade pública, decretado em 20 de março e com vigência até 31 de dezembro de 2020, dois ministros da Saúde deixaram o cargo. E, em 14 de setembro, Eduardo Pazuello, foi efetivado na função, após quatro meses como interino na pasta. Nessas transições de gestores no Ministério da Saúde, muito em discordância com o direcionamento pretendido pelo chefe do Executivo, presidente Jair Bolsonaro (sem partido), a metodologia de cálculo e a dinâmica de publicização dos dados oficiais sobre a Covid-19 no país sofreram seguidas alterações, afetando, inclusive o trabalho de divulgação dessas informações para a imprensa. A partir disso, em 8 de junho, três dos maiores grupos jornalísticos do país, responsáveis pelos veículos 0 Globo, G1, Extra, Folha de S. Paulo, UOL e O Estado de S. Paulo, emitiram um comunicado conjunto, no qual informavam que decidiram se organizar por meio de um consórcio e reunir as informações diretamente das secretarias de Saúde dos 26 estados e do Distrito Federal.

Em uma iniciativa inédita, equipes de todos os veículos vão dividir tarefas e compartilhar as informações obtidas para que os brasileiros possam saber como está a evolução e o total de óbitos provocados pela Covid-19, além dos números consolidados de casos testados e com resultado positivo para o novo coronavírus. $\mathrm{O}$ balanço diário será fechado às $20 \mathrm{~h}$.

O governo federal, por meio do Ministério da Saúde, deveria ser a fonte natural desses números, mas atitudes recentes de autoridades e do próprio presidente colocam em dúvida a disponibilidade dos dados e sua precisão.

(G1 et. al., 2020, s.p.). 
No entanto, tal iniciativa não foi muito bem recebida por alguns pesquisadores que já desenvolviam levantamentos similares. Para Katia Lerner $(2020)^{3}$, pesquisadora do Laboratório de Comunicação e Saúde do Instituto de Comunicação e Informação Científica e Tecnológica em Saúde (Laces/lcict), vinculado à Fundação Oswaldo Cruz (Fiocruz), nesse momento - de fazer diretamente a contabilização das estatísticas das secretarias de Saúde -, os veículos poderiam ter ampliado a repactuação com a ciência, uma vez que várias instituições já estavam trabalhando nessa direção. Apesar de considerar louvável a iniciativa, visto que dados a partir de uma série histórica são imprescindíveis, a coordenadora do Observatório de Saúde na Mídia questiona se caberia aos jornalistas se colocarem como responsáveis por essas informações, como se fossem sinônimo de verdade.

Tal posicionamento revela que o acirramento da disputa política em torno da pandemia não se restringiu ao âmbito dos gestores públicos e do Poder Judiciário (RICHTER, 2020), que não é o foco do trabalho em tela, mas ganhou contornos significativos ao se considerar também a mídia como partícipe desse confronto políticoargumentativo em tempos de Covid-19.

\section{O papel político da mídia durante a pandemia}

A relação entre o campo midiático e político já ocupa lugar nas agendas de pesquisa desde as primeiras décadas do século XX. Parte-se da premissa de que a mídia e a política são campos sociais diferentes e independentes, mas que se tensionam provocando uma nova arena discursiva e pragmática (LIMA, 2006; MIGUEL, 2002).

A mídia, em sua relação com a política, cumpre a função de acompanhar e monitorar os acontecimentos políticos, sendo peça importante para descortinar os arranjos políticos que, de outra forma, seriam de difícil acesso ao público. Paralelamente a essa tarefa, a mídia também se estrutura como um mercado da informação, assumindo um papel ativo que a permite acessar todo o sistema político. Ela atua como uma instância de poder, capaz de penetrar no jogo político e participar como mediadora das articulações traçadas nessa esfera, sobre as quais deveria, por princípio, informar (ALBUQUERQUE, 2000).

\footnotetext{
${ }^{3}$ Katia Lerner proferiu tal declaração durante sua participação como palestrante do minicurso "Comunicação, Mídia e Saúde em contexto de emergências sanitárias: a pandemia da Covid-19 em debate", promovido pelo curso de Jornalismo, da Universidade Federal de Alagoas, em 21 julho 2020, no formato remoto.
} 
As formas de participação da mídia na vida política são questionadas quando se alega a tentativa de influência na opinião pública em alinhamento a seu posicionamento político, a despeito de um comportamento idealmente neutro (CHAMPAGNE, 1998). Como palco de visibilidade, a mídia pode tanto aferir maior ou menor exposição a certos temas e acontecimentos, provocando percepções positivas ou negativas por parte do público. As percepções e opiniões alicerçadas por ela estão, em última instância, alinhadas a seus posicionamentos ideológicos na sociedade.

No Brasil, acontecimentos da política recente promoveram um rearranjo institucional de modo que aumentou a descrença nas instituições democráticas, e os meios de comunicação, importante fonte de informação, sobretudo, política entraram em um cenário de desconfiança. Desde as Jornadas de Junho de 2013, muitos brasileiros têm demonstrado insatisfação com a política e, sobretudo, com a classe política. De 2014 em diante, as denúncias de corrupção envolvendo a estatal Petrobras deram início às investigações da Operação Lava Jato. Com seu avanço, a corrupção foi se revelando presente em diferentes segmentos da política brasileira, a despeito das orientações ideológicas. A intensa cobertura midiática contribuiu para agravar a imagem negativa da política, de modo geral, pelos brasileiros. Em 2016, houve execução de um projeto político que incorreu no impeachment de Dilma Rousseff, com amplo apoio da grande mídia (BAPTISTA, 2018).

A eleição de 2018 se deu em um momento de crise política e econômica, em que o apelo foi direcionado a candidaturas com propostas que versassem sobre um novo fazer político, desapegado da chamada política tradicional. 0 que se viu em cena foi o crescimento da extrema direita e o impulsionamento de valores ultraconservadores. A mídia deixou de ser a fonte mais confiável de informações e no debate público, a polarização ganhou contornos de ódio e intolerância. O governo que teve início em 2019 também assumiu posicionamento contrário à grande mídia, ou melhor, a veículos que não estivessem alinhados ao projeto político vencedor, de Jair Bolsonaro. Nesse cenário, a instabilidade na relação entre a mídia e a política se intensificou.

Em 2020, no contexto da pandemia do novo coronavírus, as declarações e ações do governo Bolsonaro dividem opiniões entre os cidadãos; e não é diferente entre os veículos de mídia. As notícias sobre o curso da pandemia no Brasil e sobre os eventos relacionados à Covid-19 assumem contornos próximos ao alinhamento político dos veículos de mídia.

Este trabalho insere-se nessa discussão e busca compreender o papel político da mídia, no âmbito da pandemia do novo coronavírus no Brasil. Vale destacar que a 
pandemia não se trata apenas de um problema de saúde pública, mas envolve disputas políticas e vem intensificando as preocupações acerca das fake news, ou da desinformação, como alguns preferem denominar (ALLCOTT; GENTZKOW, 2017), colocando em risco, ao mesmo tempo, a credibilidade da mídia, a legitimidade democrática e a saúde da população. A esse respeito, podemos dizer que a opinião pública que se forma sobre a Covid-19 esbarra em notícias falsas, polarização política e entrincheira as ideologias.

\section{Metodologia}

Para este trabalho, escolhemos três telejornais brasileiros exibidos em horário nobre - Jornal Nacional - JN (Rede Globo), Jornal da Band - JB (Rede Bandeirantes) e Jornal da Record - JR (Record TV). O recorte temporal observa o dia 8 de agosto de 2020, quando o número de óbitos no Brasil por Covid-19 chegou a 100 mil vítimas.

Analisamos a cobertura jornalística do referido acontecimento a partir do método de análise do discurso, no intuito de compreender e explorar a produção de sentidos que resulta em abordagens diferentes entre os três telejornais sobre um mesmo acontecimento. Vale ressaltar a importância da narrativa da pandemia e a contextualização no estudo da cobertura jornalística, uma vez que a produção de sentidos não se descola desses componentes, tampouco se traduz como uma representação exata do real; os sentidos produzidos são direcionados ao alcance dos efeitos desejados (FOUCAULT, 1995; PÊCHEUX, 1990; POSSENTI, 1997). O silenciamento também compõe um importante aspecto relacionado à produção de sentidos que analisamos, à luz do que postula Orlandi (2000) ao demonstrar o apagamento como um lugar no discurso. 0 telejornalismo na sua condição de discurso transita entre o inter e o intradiscurso, sendo o primeiro no campo da constituição do discurso (que aciona a memória discursiva) e o segundo, da sua formulação (ORLANDI, 2000; COURTINE, 2009).

Em termos técnicos, o Jornal Nacional dedicou 39min27s (entre escalada e demais matérias) ao tema da Covid-19, do total de 1 h04min36s da edição do dia 8 de agosto. 0 Jornal da Band exibiu 12min54s (entre escalada e demais matérias) de informações sobre o novo coronavírus, de um total de $1 \mathrm{~h} 10 \mathrm{~min} 35 \mathrm{~s}$ de telejornal. O Jornal da Record, por sua vez, noticiou 11min46s (entre escalada e demais matérias) sobre a pandemia e o total da edição deste telejornal foi de 1 h03min26s. 
As 100 mil mortes, segundo os telejornais

O avanço da pandemia do novo coronavírus no Brasil é acompanhado por diversos países, na medida em que implica em mudanças na economia e nas relações políticas. 0 governo Bolsonaro divide opiniões quanto às ações tomadas no combate à doença e coleciona críticas de diversos países e organismos internacionais de saúde. $\mathrm{Na}$ mídia, a repercussão dos acontecimentos relacionados à Covid-19 movimenta a imprensa brasileira e, também, fora do país. No dia em que o Brasil registrou mais de 100 mil mortos, a notícia correu o mundo.

Figura 1. Repercussão na mídia internacional

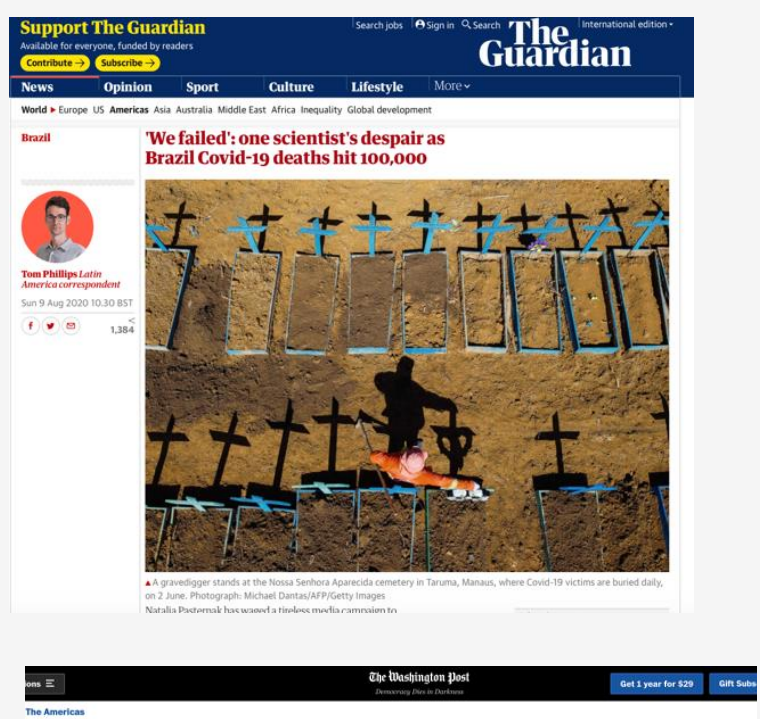

Brazil makes grim milestone -- 100,000 deaths from COVID-19

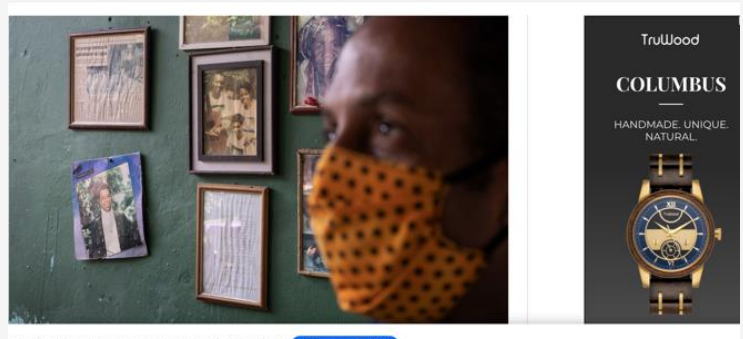

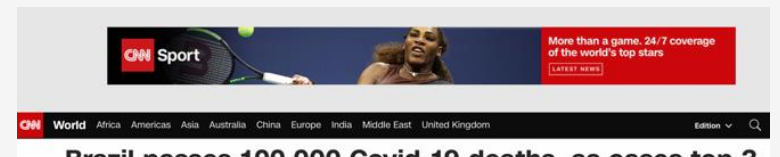

Brazil passes 100,000 Covid-19 deaths, as cases top 3 million
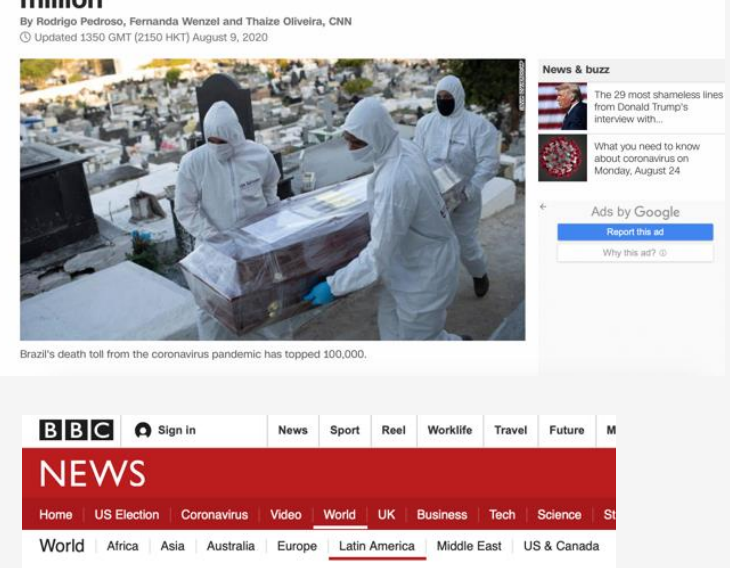

Coronavirus: Brazil passes 100,000 deaths as outbreak shows no sign of easing
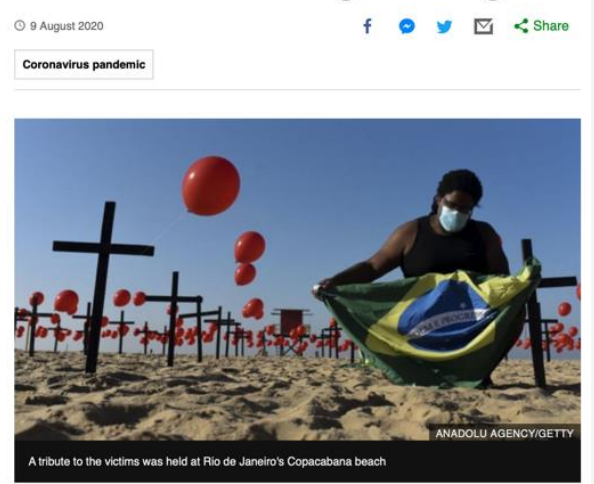

Fonte: The Guardian (2020), CNN (2020), The Washington Post (2020), BBC (2020). 
No sábado 8 de agosto, véspera do Dia dos Pais, dois fatos viraram manchetes nos três telejornais supracitados: (a) os mais de 100 mil mortos por Covid-19 no Brasil; e (b) o Palmeiras conquistara, pela quarta vez, o Campeonato Paulista, com vitória sobre o Corinthians. Somada a elas, a efeméride que também marcava a reabertura de restaurantes, lojas e shoppings em cidades como São Paulo e Porto Alegre, e era motivo de alívio e comemoração para comerciantes e dirigentes lojistas, depois de tanto tempo com estabelecimentos fechados. As edições de sábado, mais do que recortes distintos, delineiam um posicionamento político expresso pelo discurso e pela agenda encampada em cada uma das emissoras e refletida nos telejornais.

O Jornal Nacional (JN), como dito anteriormente, teve mais de $60 \%$ do tempo dedicados aos mais de 100 mil mortos pelo novo coronavírus, de acordo com os registros oficiais: a começar pelo editorial que abre o telejornal, seguindo por matérias sobre a história de algumas das vítimas ou a importância da doação de sangue, no momento em que os estoques estão vazios e há uma grande demanda devido à pandemia, ou ainda a matéria-clipe, do repórter Pedro Bassan, que encerra a edição, deixando uma pergunta no ar - “Em que país cabe tanta dor?”. A analogia a cidades com população próxima ao número de vítimas da Covid-19 e que poderiam ter desaparecido se todas essas pessoas morassem lá é reforçada como uma "tragédia que faz vítimas de todas as origens, idades, talentos e classes sociais", sem se referir à raça/cor, um quesito importante, como frisado na seção “A Covid-19 no Brasil” do artigo em tela.

Ressaltamos aqui dois pontos específicos do editorial, lido pelos apresentadores William Bonner e Renata Vasconcellos: (a) o direito constitucional e universal à saúde de todo brasileiro, que deve ser assegurado pelas autoridades de todos os níveis de poder; (b) os milhares de mortos pela Covid-19 não são meros dados estatísticos, mas pessoas que tinham história e que deixaram família, amigos, colegas de trabalho, sendo esta a perspectiva que o jornal tem adotado desde o início dos anúncios de óbitos. Com relação ao primeiro e considerando a caracterização da imprensa como um poder moderador, no sentido de exercer um compromisso político, adotada por Albuquerque (2000), o discurso do telejornal, desde as primeiras ações referentes à pandemia, é bem enfático quanto ao papel do Estado, em suas diversas instâncias, em atuar para que a população seja informada e atendida. Há uma veemente cobrança quanto a isso, inclusive. Assim, é interessante notar como Bonner destaca que Bolsonaro havia comemorado em uma rede social - Twitter - a vitória do Palmeiras, o time do qual é declaradamente torcedor; para, 
alguns minutos depois, frisar que o presidente não se manifestou pessoalmente quanto aos mais de 100 mil brasileiros vítimas do novo coronavírus, valendo-se de uma republicação de um post no Twitter da Secretaria de Comunicação do Palácio do Planalto para se posicionar a respeito.

Figura 2. Tweet de Jair Bolsonaro

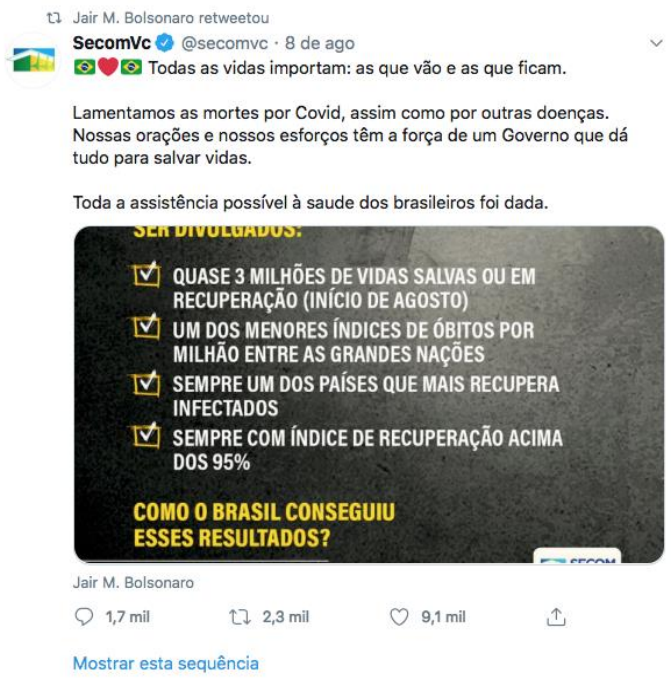

Fonte: Conta do Twitter de Jair Bolsonaro (@jairbolsonaro), em 08/08/2020.

Tal destaque vincula-se ao trecho do editorial, reproduzido a seguir, no sentido de crítica direta e enfática aos posicionamentos adotados por Bolsonaro, expressando também a opinião da emissora (REZENDE, 2000).

William Bonner: Primeiro, o presidente menosprezou a Covid; chamou de "gripezinha". Depois, quando um repórter pediu que ele falasse sobre o número alto de mortes, Bolsonaro disse que não era coveiro. Disse duas vezes: "não sou coveiro" [há um silêncio dos dois apresentadores neste momento]. Quando os óbitos chegaram a 5 mil, a resposta dele a um repórter foi um "e daí?" [mais um silêncio]. Agora, o presidente repete que "a pandemia é uma chuva e que todos vão se molhar" ou que "a morte é o destino de todos nós e que temos que enfrentar a doença", como se fosse uma questão de coragem, como se nada pudesse ter sido feito.

Renata Vasconcellos: Quando cientistas defendiam mundo afora o isolamento social como única medida capaz de conter o avanço dessa tragédia, os brasileiros viam o presidente criticar essa iniciativa diariamente, na contramão do bom senso daqueles governadores que a defendiam. $O$ resultado disso foram a confusão e a perplexidade de muitos cidadãos que ficaram sem saber em que acreditar e o isolamento capenga, insuficiente para atingir plenamente o seu objetivo. (JN, 08/08/2020). 
Também, na escalada da edição, os apresentadores realçam que, diferentemente do Congresso Nacional e do Supremo Tribunal Federal, que decretaram luto de quatro e três dias, respectivamente, em respeito às mais de 100 mil vítimas, Bolsonaro não tomou essa atitude.

Os telejornais da Band e da Record, no entanto, ao noticiarem a utilização desse protocolo comumente adotado por instituições públicas, não demarcaram que o mesmo não havia sido feito pelo chefe do Executivo. No $J B$, a decretação de luto oficial foi seguida por uma matéria que abordava as repetidas obstruções de pauta no Senado para votar a desoneração fiscal, que, mais uma vez, seria adiada em razão da homenagem às vítimas da Covid-19. Nesse trecho, chama a atenção que a única crítica que aparece ao governo federal atrela-se à oposição, visto que é exibida uma sonora do senador Rogério Carvalho, líder do PT no Senado: “Ainda não foram votados [projetos que estão aguardando votação] porque o Governo Bolsonaro tem obstruído por falta de compromisso no combate aos efeitos da pandemia na vida dos brasileiros". Já no $J R$, mesmo dizendo que era uma publicação republicada do perfil da Secretaria de Comunicação, a ênfase dada foi ao conteúdo da mensagem: "todas as vidas importam"; "lamenta as vidas perdidas e destaca orações e iniciativas para salvar vidas"; "o Brasil é um dos país que mais recupera pessoas infectadas pelo coronavírus".

Observa-se que cada telejornal acionou um tipo de interdiscurso de seu público (ORLANDI, 2000; COURTINE, 2009). Àqueles insatisfeitos com as ações de Bolsonaro no combate à pandemia, a memória mobilizada é a da crítica e do descaso, atualizada pela notícia dos 100 mil mortos com apelo a emoção, indignação, tristeza e medo. Por outro lado, o público que é alinhado às ações do presidente, notadamente, tem sua memória mobilizada a partir da satisfação e da complacência, de modo que o intradiscurso versa pelo otimismo e pelo apagamento das críticas ao não pronunciamento de Bolsonaro.

Quanto ao Dia dos Pais, data comemorativa presente também nesse fim de semana, conforme citado, em tempos que uma pandemia rege todas as ações de sociabilidade, as matérias a esse respeito, veiculadas nos três telejornais, mereceram nossa atenção e espaço na análise. Cabe destacar que, no $J B$ e no $J R$, o tom de amenidade e de que seria possível encontrar um lado positivo nessa situação tão imprevisível foi constante, marcando não apenas a matéria sobre a efeméride, como as demais relativas à Covid-19, na referida edição. Especificamente sobre a do Dia dos Pais, no $J R$, essa é matéria que encerra o telejornal e deixa no ar um sentimento de "tudo vai ficar bem", cuja analogia ao "jogo do contente" da personagem Poliana, do romance homônimo da autora 
estadunidense Eleanor H. Porter, originalmente publicado em 1913, parece-nos condizente, uma vez que, o objetivo da dinâmica adotada pela personagem é sempre obter um aprendizado ou algo positivo de uma situação grave ou aparentemente sem resolução fácil. No JR, a produção de sentido em busca do impacto desejado (FOUCAULT, 1995; PÊCHEUX, 1990; POSSENTI, 1997) pode ser compreendida dessa forma; com destaque ao que se pode aprender e boas práticas que se podem adotar como reflexo da pandemia. Ao anunciar a matéria, os apresentadores frisam que, nas datas festivas, "ficar longe aumenta ainda mais a solidão imposta pela quarentena"; assim, muitos filhos teriam que "se desdobrar para compensar essa distância. A boa notícia é que tudo vai melhorar”. A condução do texto da repórter Cleisla Garcia e as sonoras do principal entrevistado Ricardo Paulino - reiteram essa ideia:

\begin{abstract}
Cleisla Garcia: Para nos proteger e preservar a saúde daqueles que tanto queremos bem, gerações diferentes aprenderam o peso da distância física, o significado mais profundo da palavra solidão. [...] É que a solidão, aquele sentimento que já conhecemos faz tempo, parece ter se intensificado nos últimos meses. Pega muita gente de jeito, em datas especiais, como no domingo do Dia dos Pais. [imagens de pessoas idosas, em casas de repouso] [...] Por ora - e, tomara, que por pouco -, o Dia dos Pais do Seu Ângelo, pai da Rafaela, não vai reunir a família inteira, como de costume, de tradição. Vai ficar na memória o último e emocionante encontro com os pais, em janeiro, de surpresa [imagens da família de Rafaela, outra personagem da matéria]. Tempo bem aproveitado, a todo instante. Uma reserva de amor que pode até não vencer a solidão, mas traz esperança de que ela seja passageira. [...]

Ricardo Paulino: Essa pandemia, num lado, ela ajudou. Ela fez a pessoa enxergar o que ela não enxergava antes. ( $J R, 08 / 08 / 2020$, grifos nossos).
\end{abstract}

A metáfora do “jogo do contente” também pode ser utilizada na observação da matéria exibida pelo $J B$, em que o mote foi o estreitamento dos laços afetivos entre pais e filhos durante o isolamento social, com aumento da convivência diária em casa. Com três exemplos, sendo os filhos duas crianças e um adulto - médico infectologista como o pai -, a matéria frisa que a imposição de ter de realizar, em casa, a maioria das atividades cotidianas, como trabalhar e estudar, pode não ser tão desgastante ou entediante, visto que o benefício é bem mais significativo: passar mais tempo em família. No caso dos médicos infectologistas, há o destaque do compromisso em atender a um chamado, em detrimento de estar com familiares, mas que, agora sendo médico e vivenciando a urgência da pandemia, o filho entende e compartilha a escolha do pai. 
Já no JN, a homenagem do Instituto de Coleta de Sangue da Bahia ao mais antigo doador foi o mote para a comemoração da efeméride, realçando que, durante a pandemia, os estoques de sangue estão em déficit e a importância de ser doador. Arnaldo Fernandes Sant'anna doou sangue e plaquetas por 49 anos ininterruptos e agora, que atingiu 70 anos, idade que não pode mais fazer doações, levou o filho Allan, de 16 anos, para fazer o gesto de solidariedade pela primeira vez. Ver o filho seguindo seu exemplo como doador seria, portanto, seu maior presente pelo Dia dos Pais.

Há um contraponto importante aqui quanto à privatização do cuidado (TRONTO, 2013), que é a ideia de trazer para o ambiente doméstico, para a família - principalmente, para as mulheres - a responsabilidade de cuidar de outras pessoas, como crianças, idosos e aquelas com alguma dependência temporária ou permanente, e o direito universal à saúde, garantido aos brasileiros pela Constituição Federal de 1988. Tanto no JB quanto no $J R$, o tom é de que os cuidados com a Covid-19 são uma responsabilidade individual, no máximo, familiar, seja com a limpeza dos alimentos, adaptação às atuais dinâmicas de sociabilidade ou como se manter saudável física e mentalmente.

Assim, a privatização do cuidado ocupa o espaço de várias responsabilidades que caberiam ao Estado, como a infraestrutura para ensino remoto, as medidas preventivas e os tratamentos para que o vírus não se prolifere e atinja mais pessoas. $O J N$ tende a seguir mais o viés de responsabilizar o Estado e cobrar, com base na legislação vigente, pelo direito universal à saúde, que está na Carta Magna e a que todos os governantes juraram respeitar, nas palavras do editorial. Dessa forma, há uma relevante discrepância entre a agenda do telejornal da Rede Globo em comparação com os outros dois, visto que o peso dado ao registro de mais de 100 mil mortes e mais de 3 milhões de contaminados acaba por ser, de certa forma, minimizado em meio a tantas matérias que exprimem o lado positivo da quarentena.

\section{Considerações finais}

Para o desenvolvimento do presente artigo, o recorte proposto foi a cobertura de três dos principais telejornais brasileiros - Jornal Nacional, Jornal da Band e Jornal da Record - no momento em que o país havia ultrapassado o registro de 100 mil óbitos em decorrência da Covid-19. A princípio, imaginássemos que a abordagem poderia se alterar a depender da linha editorial e do público a que cada produto jornalístico e, principalmente, 
a que perspectiva a emissora estava filiada. No entanto, a análise do material coletado nos apresentou mais do que direcionamentos distintos: a coleta e a observação do corpus nos possibilitaram compreender a abrangência e a significância de sentidos diversos presentes na disputa político-discursiva dos veículos em questão.

$\mathrm{Na}$ segunda seção deste artigo, um dos pontos que abordamos mostrou que os discursos encampados pelos três telejornais individualmente, em meio à cobertura da pandemia da Covid-19 no Brasil, são politicamente situados, uma vez que comunicação, mídia, política e saúde acionam, sobretudo, sentidos e relações de poder. A implantação do Consórcio de Veículos de Imprensa a fim de centralizar os dados informados pelas secretarias de Saúde das 27 unidades da Federação, após diversas mudanças no Ministério da Saúde, é um significativo exemplo disso e do posicionamento em oposição ao governo federal, adotado pela Rede Globo, emissora de Jornal Nacional, um dos telejornais por nós observados. Outro ponto que cabe ressaltar aqui é a ênfase utilizada para destacar a saúde pública como um direito constitucional de todos os cidadãos brasileiros que não estava sendo respeitado em razão da ineficácia das políticas adotadas pelo Governo Bolsonaro, valendo-se de um pronunciamento via editorial, formato nobre e de marcação opinativa institucional do jornalismo.

Em contrapartida, os noticiários da Band e da Record adotam um tom mais ameno, inclusive com matérias que mostram perspectivas outras quanto à quarentena que, à época, já passava de cinco meses. A adoção de uma estratégia discursiva oposta à da emissora anterior tende a demonstrar uma aderência à linha desenvolvida pelo Planalto, ao mesmo tempo em que apresenta diferentes possibilidades para se experienciar a pandemia, com destaque para o estreitamento de laços familiares, a oportunidade de se repensar a rotina corrida e a possibilidade de fechar bons negócios, ou seja, não haveria apenas o lado negativo da situação. Embora, as desigualdades socioeconômicas, que sempre estiveram presentes, tenham se acirrado, durante a pandemia, num misto de incredulidade, individualismo, negacionismo e resignação.

Os telejornais falam, em nome das emissoras, a um público que anseia por um determinado agendamento dos fatos. A adesão ao "jogo do contente" talvez tenha mais a nos dizer do que uma mera descrença ou alienação, que pode ser a percepção primeira de quem observa de fora. No jogo político-midiático, que a outra faceta também se insere, às personagens cabe privatizar o cuidado, sub-considerar a responsabilidade de governos, mas não cabe naturalizar a perda de tantas vidas que poderiam ter sido poupadas. 


\section{Referências}

AGENCE France-Presse (AFP). Mundo supera 800 mil mortes por covid-19 e aumenta alerta de novos surtos. Uol, 22 ago. 2020. Disponível em: <https://noticias.uol.com.br/ultimasnoticias/afp/2020/08/22/mundo-supera-as-800000-mortes-por-covid-19-e-aumenta-alertade-novos-surtos.htm>. Acesso em: 23 ago. 2020.

ALBUQUERQUE, A. Um outro "quarto poder": imprensa e compromisso político no Brasil. Contraponto, Niterói, n. 4, p. 23-57, jan. 2000.

ALLCOTT, H.; GENTZKOW, M. Social media and fake news in the 2016 election. Journal of Economic Perspectives, v. 31, n. 2, spring 2017, pp. 211-236.

BAPTISTA, E. A. Corrupção política e avaliação de governo: o caso da Lava Jato. Aurora, São Paulo, v. 11, n. 32, p. 128-148, 2018.

BRASIL. Decreto Legislativo n. 6, de 2020. Reconhece, para os fins do art. 65 da Lei Complementar $\mathrm{n}^{\circ} 101$, de 4 de maio de 2000, a ocorrência do estado de calamidade pública, nos termos da solicitação do Presidente da República encaminhada por meio da Mensagem $\mathrm{n}^{\circ}$ 93, de 18 de março de 2020. Disponível em: <http://www.planalto.gov.br/ccivil_03/portaria/DLG6-2020.htm>. Acesso em: 23 ago. 2020.

CHAMPAGNE, P. Formar a opinião: o novo jogo político. Trad. Guilherme João de Freitas Teixeira. Petrópolis: Vozes, 1998.

CORONAVIRUS: Brazil passes 100,000 deaths as outbreak shows no sign of easing. BBC, 9 ago. 2020. Disponível em: <https://www.bbc.com/news/world-latin-america-53712087>. Acesso em: 23 ago. 2020.

COURTINE, J-J. Análise do discurso político. O discurso comunista endereçado aos cristãos. São Carlos: EdUFSCar, 2009.

FOUCAULT, M. A arqueologia do saber. Rio de Janeiro: Forense Universitária, 1995.

FRANÇA, V. V. Jornalismo e vida social. Belo Horizonte: Editora da UFMG, 1998.

FREITAS, V. G. As mulheres negras e a pandemia do coronavírus. Boletim Cientistas Sociais e o Coronavírus, n. 44, 20 maio 2020. Disponível em: <http://anpocs.org/index.php/publicacoes-sp-2056165036/boletim-cientistassociais/2362-boletim-n-44-cientistas-sociais-e-o-coronavirus>. Acesso em: 20 maio 2020. 
G1 et al. Veículos de comunicação formam parceria para dar transparência a dados de Covid-19. G1, 8 de jun. 2020. Disponível em: <https://g1.globo.com/politica/noticia/2020/06/08/veiculos-de-comunicacao-formamparceria-para-dar-transparencia-a-dados-de-covid-19.ghtml>. Acesso em: 23 ago. 2020.

G1. Casos e mortes por coronavírus no Brasil em 23 de agosto, segundo consórcio de veículos de imprensa (atualização das 13h). G1, 23 ago. 2020. Disponível em: <https://g1.globo.com/bemestar/coronavirus/noticia/2020/08/23/casos-e-mortes-porcoronavirus-no-brasil-em-23-de-agosto-segundo-consorcio-de-veiculos-de-imprensa.ghtml>. Acesso em: 23 ago. 2020.

JORNAL da Band. Edição de 8 de agosto de 2020. Disponível em: <https: / /www.youtube.com/watch?v=zwFtpB9-neA>. Acesso em: 14 ago. 2020.

JORNAL da Record. Edição de 8 de agosto de 2020. Disponível em: <https://www.youtube.com/watch?v=Bm_KS9NYTIQ>. Acesso em: 14 ago. 2020.

JORNAL Nacional. Edição de 8 de agosto de 2020. Disponível em: <https://globoplay.globo.com/v/8763064/programa/>. Acesso em: 14 ago. 2020.

LERNER, K. A pandemia em perspectiva: reflexões sobre a Covid-19 em estudos sobre mídia e saúde. Minicurso "Comunicação, Mídia e Saúde em contexto de emergências sanitárias: a pandemia da Covid-19 em debate", Universidade Federal de Alagoas, 21 jul. $2020 . \quad$ Disponível em: <https: / /www.youtube.com/watch?v=Ebq6tx8kSi0\&feature=youtu.be>. Acesso em: 21 jul. 2020.

LIMA, V. Mídia: crise política e poder no Brasil. São Paulo: Editora Perseu Abramo, 2006.

MIGUEL, L. F. Os meios comunicação e a prática política. Lua Nova, São Paulo, n. 55-56, 2002, p. 155-184.

ORLANDI, E. Análise de discurso: princípios e procedimentos. 2.ed. Campinas: Pontes, 2000.

PÊCHEUX, M. Análise automática do discurso. In: GADET, F. HAK. T. (orgs). Por uma análise automática do discurso: uma introdução à obra de Michel Pếcheu. Campinas: UNICAMP, 1990, p. 61-105.

PEDROSO, R.; WENZEL, F.; OLIVEIRA, T. Brazil passes 100,000 Covid-19 deaths, as cases top 3 million. $\mathrm{CNN}, \quad 9$ ago. 2020. Disponível em: <https://edition.cnn.com/2020/08/08/world/brazil-covid-19-deaths-intl/index.html>. Acesso em: 23 ago. 2020. 
PHILLIPS, T. 'We failed': one scientist's despair as Brazil Covid-19 deaths hit 100,000. The Guardian, 9 ago. 2020. Disponível em: <https://www.theguardian.com/world/2020/aug/09/brazil-covid-19-deaths-nataliapasternak-bolsonaro>. Acesso em: 23 ago. 2020.

PORTER, E. H. Poliana. Rio de Janeiro: Nova Fronteira, 2018.

POSSENTI, S. Sobre as noções de sentido e de efeito de sentido. Cadernos da F.F.C. Análise do Discurso, v. 6, n. 2. p. 1-11, 1997.

PRADO, M. F. et al. Analysis of COVID-19 under-reporting in Brazil. Revista Brasileira de Terapia Intensiva, v. 32, n. 2, p. 224-228, jun. 2020.

REZENDE, G. J. Telejornalismo no Brasil: um perfil editorial. São Paulo: Summus, 2000.

RICHTER, A. STF: estados e municípios podem fazer ações contra covid-19 sem União. Agência Brasil, 15 abr. 2020. Disponível em: <https://agenciabrasil.ebc.com.br/justica/noticia/2020-04/stf-estados-e-municipiospodem-fazer-acoes-contra-covid-19-sem-uniao>. Acesso em: 23 ago. 2020.

RIGUES, R. Primeiros casos do novo coronavírus são mais antigos do que se pensava. Olhar Digital, 16 mar. 2020. Disponível em: <https://olhardigital.com.br/coronavirus/noticia/primeiros-casos-do-novo-coronavirussao-mais-antigos-do-que-se-pensava/98084>. Acesso em: 23 ago. 2020.

SOUSA, M. Brazil makes grim milestone - 100,000 deaths from COVID-19. Washington Post, 8 ago. 2020. Disponível em: <https: / /www.washingtonpost.com/world/the_americas/brazil-near-100000-deaths-fromcovid-19/2020/08/08/df6dcd66-d995-11ea-a788-2ce86ce81129_story.html>. Acesso em: 23 ago. 2020.

TRONTO, J. Caring democracy: markets, equality, and justice. New York: New York University Press, 2013.

WORLD Health Organization (WHO). Q\&A on coronaviruses (COVID-19). 12 out. 2020. Disponível em: <https://www.who.int/emergencies/diseases/novel-coronavirus2019/question-and-answers-hub/q-a-detail/q-a-coronaviruses>. Acesso em: 23 ago. 2020.

ZEIGLER, M. F. Coronavírus: estimativa aponta número de casos $14 x$ maior do que o oficial. Agência Fapesp, Veja Saúde, 8 maio 2020. Disponível em: <https://saude.abril.com.br/medicina/coronavirus-estimativa-aponta-numero-de-casos14x-maior-do-que-o-oficial/>. Acesso em: 23 ago. 2020. 


\section{Como citar este artigo}

FREITAS, Viviane Gonçalves; BAPTISTA, Érica Anita. 100 mil mortes: o saldo negativo da Covid-19 nos telejornais brasileiros. Revista Dispositiva. [on-line] Disponível em: <http://periodicos.pucminas.br/index.php/d ispositiva> Dossiê: Comunicação, política e saúde. Editoras Responsáveis: Fernanda Sanglard e Vanessa Veiga de Oliveira. Volume 9 , Número 16, Belo Horizonte, dezembro de 2020, p. 50-67. Acesso em “dia/mês/ano".

Texto recebido em: $24 / 08 / 2020$

Texto aprovado em: 16/11/2020 